Check for updates

Cite this: RSC Adv., 2019, 9, 25240

\title{
Iron phosphide anchored nanoporous carbon as an efficient electrode for supercapacitors and the oxygen reduction reaction $\uparrow$
}

\author{
Ahmed K. Yousef, ${ }^{a}$ Yena Kim, (DD *bc Piyali Bhanja, (D) *c Peng Mei, (D) cd \\ Malay Pramanik, ${ }^{C}$ M. M. S. Sanad, (D) e M. M. Rashad, (D) e A. Y. El-Sayed, ${ }^{a}$ \\ Abdulmohsen Ali Alshehri, ${ }^{f}$ Yousef Gamaan Alghamdi, ${ }^{f}$ Khalid Ahmed Alzahrani, ${ }^{f}$ \\ Yusuke Ide, (D) ${ }^{c}$ Jianjian Lin (D) ${ }^{b}$ and Yusuke Yamauchi (D)*gh
}

\begin{abstract}
Inspired by their distinctive properties, transition metal phosphides have gained immense attention as promising electrode materials for energy storage and conversion applications. The introduction of a safe and large-scale method of synthesizing a composite of these materials with carbon is of great significance in the fields of electrochemical and materials sciences. In the current effort, we successfully synthesize an iron phosphide/carbon (FeP/C) with a high specific surface area by the pyrolysis of the gel resulting from the hydrothermal treatment of an iron nitrate-phytic acid mixed solution. In comparison with the blank $(\mathrm{P} / \mathrm{C})$, the as-synthesized $\mathrm{FeP} / \mathrm{C}$ appears to be an efficient electrode material for supercapacitor as well as oxygen reduction reaction (ORR) applications in an alkaline medium in a threeelectrode system. In the study of supercapacitors, $\mathrm{FeP} / \mathrm{C}$ shows areal capacitance of $313 \mathrm{mF} \mathrm{cm}{ }^{-2}$ at 1.2 $\mathrm{mA} \mathrm{cm}{ }^{-2}$ while retaining $95 \%$ of its initial capacitance value after 10000 cycles, while in the ORR, the synthesized material exhibits high electrocatalytic activity with an onset potential of ca. $0.86 \mathrm{~V}$ vs. RHE through the preferred four-electron pathway and less than $6 \% \mathrm{H}_{2} \mathrm{O}_{2}$ production calculated in the potential range of $0.0-0.7 \mathrm{~V}$ vs. RHE. The stability is found to be better than those of the benchmark Pt/

C (20 wt\%) catalyst.
\end{abstract}

rsc.li/rsc-advances

\section{Introduction}

Searching for a new renewable, low-cost, and environmentally friendly source for energy storage and/or conversion has become one of the hottest research challenges, driven by diminishing fossil

${ }^{a}$ Chemistry Department, Faculty of Science, Al-Azhar University, Assiut Branch, 71524 Assiut, Egypt

${ }^{b}$ Key Laboratory of Eco-Chemical Engineering, College of Chemistry and Molecular Engineering, Qingdao University of Science and Technology, Qingdao 266042, China

'International Center for Materials Nanoarchitectonics (WPI-MANA), National Institute for Materials Science (NIMS), 1-1 Namiki, Tsukuba, Ibaraki 305-0044, Japan.E-mail: piyalibhanja4@gmail.com; yenakim1227@gmail.com

${ }^{d}$ School of Chemistry and Materials Science, South-Central University for Nationalities, Wuhan 430074, China

${ }^{e}$ Central Metallurgical Research \& Development Institute, P.O. Box 87, Helwan 11421, Egypt

${ }^{f_{\text {Department }}}$ of Chemistry, King Abdulaziz University, P.O. Box. 80203, Jeddah 21589, Saudi Arabia

${ }^{8}$ School of Chemical Engineering, Australian Institute for Bioengineering and Nanotechnology (AIBN), The University of Queensland Brisbane, QLD 4072, Australia.E-mail: y.yamauchi@uq.edu.au

${ }^{h}$ Department of Plant \& Environmental New Resources, Kyung Hee University, 1732 Deogyeong-daero, Giheung-gu, Yongin-si, Gyeonggi-do 446-701, South Korea

$\dagger$ Electronic supplementary information (ESI) available. See DOI: $10.1039 / \mathrm{c} 9 \mathrm{ra} 04326 \mathrm{~h}$ fuel supplies and climate change in addition to ever-increasing demands for energy sources..$^{1,2}$ Thus, supercapacitors and oxygen reduction reaction (ORR) have been considered the best way out for the current and near future energy issues. ${ }^{3}$ Supercapacitor devices can be made using non-toxic materials and show characteristic properties such as a superior power density, long cycle life, and high charge-discharge efficiency as compared with conventional batteries. ${ }^{4-6}$ The ORR is crucial in our daily life processes, and it is one of the most important reactions in energy storage and conversion applications, where it is the heart of metal-air batteries and fuel cells. ${ }^{7-9}$

The electrical energy in supercapacitors can be stored on the electrode surface in two ways. First, the electrolyte ions are adsorbed at the electrical double layer to produce what is called electric double layer capacitors (EDLCs), and a second one is by redox reactions, which are called pseudocapacitors. ${ }^{10-12}$ Depending on the nature of the electrode materials, the electrical energy storage mechanism could be controlled. Metal oxides and conductive polymers are the main materials used for pseudocapacitors, while carbon is the conventional electrode material used for EDLCs. ${ }^{13}$ In general, a high-performance supercapacitor requires materials with high electrical conductivity and a large ion-accessible surface area. In addition, a high ionic transport rate requires short ion diffusion length 
throughout the electrode materials. ${ }^{14}$ On the other hand, ORR reacts sluggishly, and it needs to be facilitated to improve its efficiency. Although Pt is the current state-of-the-art electrocatalyst for this reaction, intensive research to modify or replace it is ongoing owing to its high cost and finite resource. ${ }^{15-17}$

In spite of the recently obtained performance of both supercapacitors and ORR, with the rapid development of electronic devices and the extension of their applications toward large-scale devices, much higher performance is required through the improvement of properties such as energy density, rate capability, cyclability, and safety. The development of new electrode materials plays a vital role in reaching the required performance to promote the commercialization of the two applications mentioned above..$^{18-21}$ Transition metal compounds are an important class of functional electrode materials that have been widely investigated in several energy applications. ${ }^{22-25}$ In an inert atmosphere, transition metals combine with phosphorus chemicals to form transition metal phosphides (TMPs), and these materials have notable potential toward energy storage and electrocatalytic applications due to their advantages of low cost, easy large-scale synthesis, and interesting electrical properties. ${ }^{26}$ Among TMPs, iron phosphide (FeP) has been considered as a promising energy electrode material because $\mathrm{Fe}$ is naturally abundant and has low cost, low toxicity, and negligible environmental impact. ${ }^{27}$ However, some synthetic methods for producing this kind of material are dangerous (for example, the use of $\mathrm{H}_{2}$ to produce $\mathrm{PH}_{3}$ gas). ${ }^{26,28}$ Moreover, the poor stability of ironbased materials limits their electrochemical properties. ${ }^{29-32}$ Thus, its combination with carbon is an effective strategy for keeping structural stability, improving electronic conductivity during cycling, and obtaining high surface area materials. ${ }^{33-35}$ Accordingly, providing a safe synthetic method to obtain $\mathrm{FeP} /$ carbon (FeP/C) materials with high surface areas and high stability while exploring their performance as supercapacitors and ORR are highly important for satisfying the current needs for energy.

In this study, we report a facile and safe method for the synthesis of FeP/C with a high surface area through a pyrolysis strategy for the gel resulting from the hydrothermal treatment of $\mathrm{Fe}$ nitrate-phytic acid mixed solution. When the assynthesized $\mathrm{FeP} / \mathrm{C}$ is used as an electrode for a supercapacitor, it exhibits good areal capacitance and shows outstanding cycle performance (retains $95 \%$ of its initial capacitance value after 10000 cycles), which indicates the promising practical applications of synthesized $\mathrm{FeP} / \mathrm{C}$ for supercapacitors. The electrocatalytic performance towards ORR in an alkaline medium is also investigated. The obtained FeP/C electrodes show electrocatalytic activity through a four-electron reaction pathway that was higher than that of $\mathrm{P} / \mathrm{C}$ samples. In addition, the limiting current density at $0 \mathrm{~V} v s$. RHE and stability are found to be better than those of the benchmark Pt/ C (20 wt\%) catalyst.

\section{Experimental section}

\section{Materials}

Iron nitrate nonahydrate $\left(\mathrm{Fe}\left(\mathrm{NO}_{3}\right)_{3} \cdot 9 \mathrm{H}_{2} \mathrm{O}\right)$, isopropanol, ethanol, methanol, and $\mathrm{KOH}$ were purchased from Wako Pure Chemicals Co., Ltd. Phytic acid solution ( $50 \mathrm{wt} \%$ in $\mathrm{H}_{2} \mathrm{O}$ ) and
Nafion solution (5 wt\%) were purchased from Sigma-Aldrich, and commercial Pt/C (20 wt\%) from Alfa Aesar. Carbon Paper TGP-H-090 was obtained from Toray. All chemicals were of analytical grade and were used without further treatment.

\section{Synthesis of $\mathrm{FeP} / \mathrm{C}$ and $\mathrm{P} / \mathrm{C}$}

In a typical synthesis procedure, $0.5 \mathrm{mmol}$ of $\mathrm{Fe}\left(\mathrm{NO}_{3}\right)_{3} \cdot 9 \mathrm{H}_{2} \mathrm{O}$ was added to $10 \mathrm{mmol}$ of phytic acid solution, and it was continuously stirred for one hour. The resultant clear solution was transferred to a $25 \mathrm{~mL}$ stainless steel autoclave and heated to $140{ }^{\circ} \mathrm{C}$ at a rate of $1{ }^{\circ} \mathrm{C} \mathrm{min}{ }^{-1}$ and left for $36 \mathrm{~h}$. The resulting gel was transferred to a tubular furnace and left in a nitrogen atmosphere at room temperature for $1 \mathrm{~h}$; after that, the temperature was increased to $300{ }^{\circ} \mathrm{C}$ and maintained for $2 \mathrm{~h}$. Subsequently, the temperature was increased to $900{ }^{\circ} \mathrm{C}$ and maintained for $2 \mathrm{~h}$. Finally, the sample was naturally cooled. The heating rate for the entire annealing process was $5{ }^{\circ} \mathrm{C} \mathrm{min}^{-1}$. After cooling to room temperature, a black powder material of $\mathrm{FeP} / \mathrm{C}$ was obtained. $\mathrm{P} / \mathrm{C}$ was prepared through the same procedure without adding Fe salt with a slight modification, where the gel resulting from the hydrothermal treatment was washed once with methanol and dried at $60{ }^{\circ} \mathrm{C}$ for one day before annealing.

\section{Characterization}

Wide-angle powder X-ray diffraction (XRD) patterns were collected on a Rigaku SmartLab X-ray diffractometer using $\mathrm{Cu}$ $\mathrm{K} \alpha$ radiation $(40 \mathrm{kV}$ and $30 \mathrm{~mA})$ at a scanning rate of $1^{\circ} \mathrm{min}^{-1}$. Raman spectroscopy was acquired with a HORIBA Scientific Lab RAM HR Raman spectrometer system using $532.4 \mathrm{~nm}$ laser excitation. Field-emission SEM measurements were performed on a HITACHI SU-8230 to check the morphologies. Investigation of the inner structure and energy-dispersive X-ray spectroscopy (EDS) elemental mapping were carried out using a transmission electron microscope (TEM, JEOL JEM-2100F). The nitrogen adsorption-desorption of the samples was measured on a Micromeritics BK122T-B analyzer. The Brunauer-Emmett-Teller (BET) theory was used for the specific surface area (SSA) determination in the relative pressure range of 0.05-0.30. Pore size distributions were determined from the adsorption isotherms, according to the quenched solid-state density functional theory (QSDFT) assuming a mixed cylinder/ sphere pore model. Inductively coupled plasma optical emission spectroscopy (ICP-OES) was done on a Hitachi High-Tech Science Corporation model SPS3520UV-DD. The standard was made by Kanto Chemical Co., Inc., and the qualified standard solution by JCSS. The samples were fused by a mixture of $\mathrm{Na}_{2} \mathrm{CO}_{3}, \mathrm{H}_{3} \mathrm{BO}_{3}, \mathrm{KNO}_{3}$ and $\mathrm{K}_{2} \mathrm{~S}_{2} \mathrm{O}_{7}$ salts to digest the material into a dissoluble solid. During this process carbon burns out and removed as $\mathrm{CO}_{2}$, Remaining solid melt was then dissolved in $\mathrm{HNO}_{3}$ for the chemical analysis.

\section{Electrochemical measurements}

The electrochemical performances of the prepared electrodes were investigated with a three-electrode system. 
For supercapacitor measurements. Homogeneous ink was prepared as follows. First, the as-prepared FeP/C and P/C were ground, and then $4.0 \mathrm{mg}$ of solid material was dispersed into $380 \mu \mathrm{L}$ of an isopropanol/water mixed solution (volume ratio of $2: 1$ ) and $20 \mu \mathrm{L}$ of $5.0 \mathrm{wt} \%$ Nafion. After $30 \mathrm{~min}$ sonication, 120 $\mu \mathrm{L}$ of the suspension was dropped onto carbon paper (thickness: $1 \mathrm{~mm}$ ) with an area of $1 \times 1 \mathrm{~cm}^{2}$ and dried overnight at $60{ }^{\circ} \mathrm{C}$. The mass loading was $1.2 \mathrm{mg} \mathrm{cm}^{-2}$. All electrochemical measurements were carried out using a CHI 660E instrument; cyclic voltammetry (CV) and galvanostatic charge-discharge (GCD) measurements were carried out in $3 \mathrm{M} \mathrm{KOH}$ between -0.8 and $0.0 \mathrm{~V}$ vs. SCE, with a platinum wire and saturated calomel electrode (SCE) as a counter and a reference electrode, respectively. The test of long-term stability for $\mathrm{FeP} / \mathrm{C}$ was conducted by cycling between -0.8 and $0.0 \mathrm{~V} v s$. SCE in $3 \mathrm{M} \mathrm{KOH}$ at a scan rate of $100 \mathrm{mV} \mathrm{s}^{-1}$.

The gravimetric specific capacitances $\left(C_{\mathrm{g}}, \mathrm{F} \mathrm{g} \mathrm{g}^{-1}\right)$ of the assynthesized electrodes were calculated from the GCD curves using the following equation:

$$
C_{\mathrm{g}}=(I \times \Delta t) /(m \times \Delta V),
$$

where $I$ is the discharge current (A), $\Delta t$ is the discharge time difference (s), $m$ is the mass of the active material (g), and $\Delta V$ is the potential change during the discharge process $(\mathrm{V})$.

The areal capacitance $\left(C_{\mathrm{A}}, \mathrm{mF} \mathrm{cm}^{-2}\right)$ was calculated using the following equation:

$$
C_{\mathrm{A}}=C_{\mathrm{g}} \times m_{\mathrm{l}},
$$

where $m_{1}$ is the mass loading of the sample $\left(\mathrm{mg} \mathrm{cm}^{-2}\right)$.

For ORR measurements. First, the homogeneous ink was prepared as follows. The as-prepared $\mathrm{FeP} / \mathrm{C}$ and $\mathrm{P} / \mathrm{C}$ were ground, and then $5.0 \mathrm{mg}$ of the solid material was dispersed into $950 \mu \mathrm{L}$ of an ethanol : water mixed solution (volume ratio of $1: 3$ ) and $50 \mu \mathrm{L}$ of $5.0 \mathrm{wt} \%$ Nafion. After sonication for $60 \mathrm{~min}, 5 \mu \mathrm{L}$ of the suspension was dropped onto a glassy carbon electrode (GCE) of a rotating ring-disk electrode (RRDE) with an area of $0.1256 \mathrm{~cm}^{2}$ and dried under a lamp. The mass loading was $0.2 \mathrm{mg} \mathrm{cm}^{-2}$. To activate the GCE, it was prepolished with $1 \mu \mathrm{m}$ diamond, then $0.05 \mu \mathrm{m}$ alumina powder, and washed with water. All electrochemical measurements were carried out using CHI 842B instrument; cyclic voltammetry (CV), linear sweep voltammetry (LSV) at $10 \mathrm{mV} \mathrm{s}^{-1}$, and chronoamperometry $(i-t)$ measurements were performed in $0.1 \mathrm{M}$ $\mathrm{KOH}$ saturated solution. The electrolyte solution was continuously purged with ultra-pure $\mathrm{O}_{2}$ or $\mathrm{N}_{2}$ for at least $1 \mathrm{~h}$ before starting the measurements. A platinum wire and silver-silver chloride $(\mathrm{Ag} / \mathrm{AgCl})$ were used as the counter and reference electrode, respectively. The potentials were expressed with regard to the reversible hydrogen potential electrode (RHE). The overall electron transfer numbers per oxygen molecule were calculated from the slope of the Koutecky-Levich (K-L) plots according to the following equation:

$$
J^{-1}=J_{\mathrm{k}}^{-1}+J_{\mathrm{L}}^{-1}=J_{\mathrm{k}}^{-1}+B^{-1} \omega^{-1 / 2}
$$

$$
B=0.2 n F C_{\mathrm{o}}\left(D_{\mathrm{o}}\right)^{2 / 3} \nu^{-1 / 6}
$$

where $J$ is the current density, $J_{\mathrm{k}}$ is the kinetic current density, $J_{\mathrm{L}}$ is the diffusion-limited current density, $n$ is the transferred electron number, $F$ is the Faraday constant $(F=96485 \mathrm{C}$ $\left.\mathrm{mol}^{-1}\right), C_{\mathrm{o}}$ is the concentration of $\mathrm{O}_{2}\left(1.2 \times 10^{-6} \mathrm{~mol} \mathrm{~cm}{ }^{-3}\right), D_{\mathrm{o}}$ is the diffusion coefficient of $\mathrm{O}_{2}\left(1.9 \times 10^{-5} \mathrm{~cm}^{2} \mathrm{~s}^{-1}\right), \nu$ is the kinematic viscosity of the electrolyte $\left(0.01 \mathrm{~cm}^{2} \mathrm{~s}^{-1}\right)$, and $\omega$ is the electrode rotating speed in $\mathrm{rpm}(0.2$ is a constant when the rotating speed is expressed in rpm). ${ }^{36,37} n$ and $\% \mathrm{H}_{2} \mathrm{O}_{2}$ were calculated from RRDE measurements according to the following equations:

$$
n=4 \times I_{\mathrm{d}} /\left[I_{\mathrm{d}}+\left(I_{\mathrm{r}} / N\right)\right]
$$

$I_{\mathrm{d}}$ is the disk current, $I_{\mathrm{r}}$ is the ring current, and $N$ is the collection efficiency of the ring (0.37).

$$
\% \mathrm{H}_{2} \mathrm{O}_{2}=200 \times\left(I_{\mathrm{r}} / N\right) /\left[I_{\mathrm{d}}+\left(I_{\mathrm{r}} / N\right)\right] .
$$

\section{Results and discussion}

FeP/C was synthesized through a two-step process involving hydrothermal solution-phase crystallization and carbonization under inert atmosphere. During the crystallization process, the clear mixtures of the phytic acid and Fe(III) precursor solutions undergo polycondensation from the initial gel through the hydrothermal treatment at $140{ }^{\circ} \mathrm{C}$ for $36 \mathrm{~h}$. Under these conditions, the phytic acid molecule, which bears six phosphonic acid moieties, has a strong affinity to bind with $\mathrm{Fe}$ (III) species present in the synthesis medium to form a highly crosslinked structure via the $\mathrm{Fe}-\mathrm{O}-\mathrm{P}$ bonds. The cross-linking increased during the hydrothermal treatment, leading to improved mechanical strength of the metal-ligand network structure. ${ }^{38}$ The multidentate nature of the phytic acid molecule together with the presence of $\mathrm{PO}_{4}$ tetrahedral and $\mathrm{FeO}_{6}$ octahedral units separated by organic fragments could provide high structural robustness, as reflected in the crystalline nanostructure. Finally, the pyrolysis of the resulted cross-linked structure at a high temperature leads to the decomposition of $\mathrm{Fe}$-phytate and the interaction of $\mathrm{Fe}$ with $\mathrm{P}$ to form $\mathrm{FeP}$ nanoclusters, while the phytate rings carbonized to obtain $\mathrm{FeP} / \mathrm{C}$ as a final product.

The XRD patterns of $\mathrm{P} / \mathrm{C}$ and $\mathrm{FeP} / \mathrm{C}$ are shown in Fig. 1a. All $\mathrm{XRD}$ peaks in the $\mathrm{FeP} / \mathrm{C}$ sample can be indexed as pure $\mathrm{FeP}$ (JCPDS card no. 89-2746) with the presence of two broad characteristic graphitic peaks located at around $23^{\circ}$ and $43^{\circ}$ in both samples, which can be assigned to (002) and (101) planes, respectively. Raman analysis was used to investigate the graphitic degree of the carbon content in the synthesized samples. As can be seen in Fig. 1b, both samples exhibit typical $D$ and $G$ bands at 1353 and $1596 \mathrm{~cm}^{-1}$, representing the disordered and graphitic phases in carbon, respectively. Therefore, the integrated intensity ratio of $\mathrm{D}$ and $\mathrm{G}$ bands can reveal the level of ordering and defects in the carbon structure, 

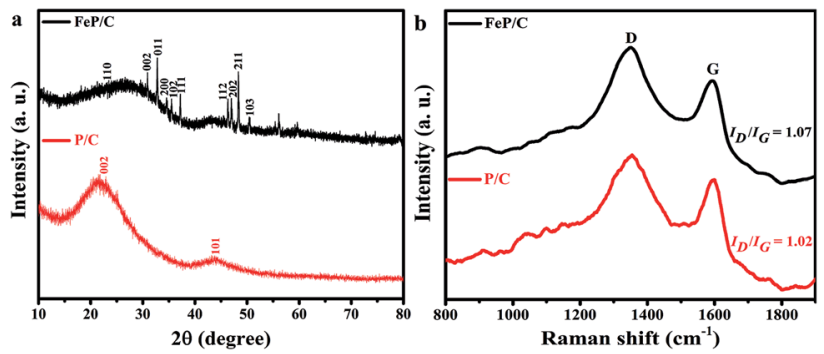

Fig. 1 (a) XRD patterns and (b) Raman spectra of P/C and FeP/C

indicating a higher disorder for a higher $I_{\mathrm{D}} / I_{\mathrm{G}}$ value. ${ }^{39} I_{\mathrm{D}}$ is higher than $I_{\mathrm{G}}$ in the two samples, and the intensity ratio of $I_{\mathrm{D}} /$ $I_{\mathrm{G}}$ is about 1.02 and 1.07 for $\mathrm{P} / \mathrm{C}$ and $\mathrm{FeP} / \mathrm{C}$, respectively. This indicates that many defects or disordered sites are present in the carbon component, which agrees with the obtained XRD data.

The morphology of the $\mathrm{P} / \mathrm{C}$ and $\mathrm{FeP} / \mathrm{C}$ materials were investigated using scanning electron microscopy (SEM) (Fig. 2a and b). As shown in Fig. 2a, the P/C possesses irregularly shaped particles, with the presence of some spherical particles (as indicated by arrows). However, the FeP/C appears as a stacked layered structure with no distinct particles, as can be seen in its SEM image (Fig. 2b and S2b†). Thus, the morphology has been changed from $\mathrm{P} / \mathrm{C}$ to $\mathrm{FeP} / \mathrm{C}$, which is understandable where the temperature is high enough to cause a reaction of Fe particles with the carbon matrix to form Fe carbide, which, with increasing temperature, dissociates again into graphitic carbon and Fe particles. ${ }^{40} \mathrm{~A}$ variety of graphitic carbons of small crystallite size are supposed to be formed, as the graphitization effect of the Fe particle is localized. The high temperature $(900$ ${ }^{\circ} \mathrm{C}$ ) and the presence of the Fe particle enhance the degree of graphitization. ${ }^{41}$ The amorphous nature of the synthesized materials and the disordered micropores were observed under

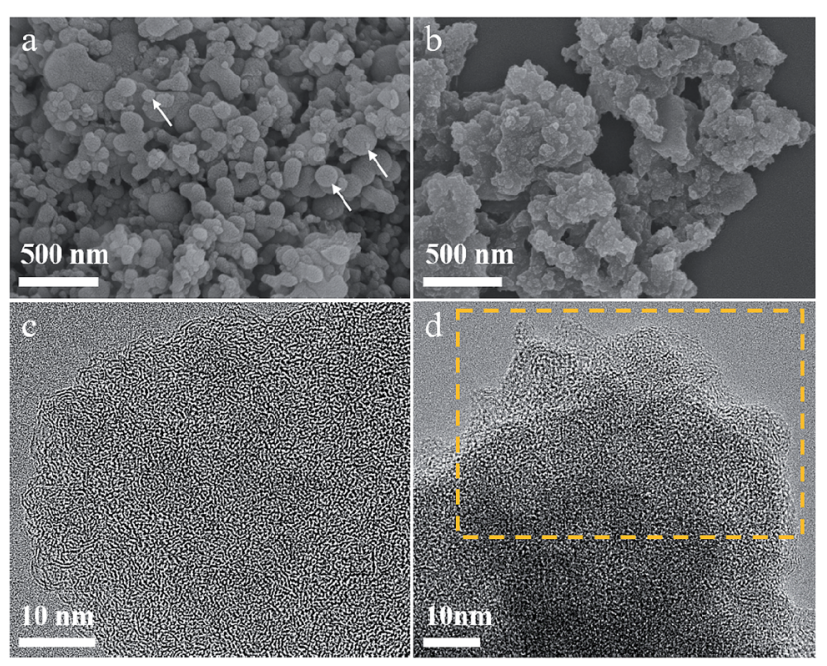

Fig. 2 ( $a$ and b) SEM and ( $c$ and d) HRTEM images of ( $a$ and $c$ ) P/C and (b and d) FeP/C, respectively. The white arrows in (a) indicate the presence of spherical particles in the P/C sample. The yellow box in (d) indicates the layered-like structure of FeP/C. a high-resolution transmission electron microscope (HRTEM), as shown in Fig. 2c, $d$ and S1. $\dagger$ The HRTEM images indicate the layered-like structure of synthesized FeP/C samples, highlighted by the yellow boxes in Fig. $2 \mathrm{~d}$ and S2. $\dagger$ This sheet-like structure can improve the electrocatalytic performance of active materials through fast electron transfer and ion diffusion pathways, and can also increase the effective contact area between the electrolytes and active materials. ${ }^{42,43}$ Elemental mapping of $\mathrm{FeP} / \mathrm{C}$ shows the uniform distribution of Fe and $\mathrm{P}$ elements over the carbon matrix, as can be seen in Fig. S3. $\dagger$ From this elemental mapping, it is noticed that the amount of $\mathrm{P}$ element is higher than that of $\mathrm{Fe}$, which is different from the results obtained by XRD $(1: 1)$. From ICP analysis, the amount of $\mathrm{P}$ in the $\mathrm{P} / \mathrm{C}$ sample was found to be $20 \%$, while in the $\mathrm{FeP} / \mathrm{C}$ sample, the amount of $\mathrm{P}$ was $15 \%$ and of Fe was $7 \%$, indicating the dominant content of $\mathrm{C}$ in both samples (80\%). That may explain its amorphous appearance, as shown in Fig. 2c and d.

The specific surface area and pore size of $\mathrm{P} / \mathrm{C}$ and $\mathrm{FeP} / \mathrm{C}$ were examined by nitrogen adsorption-desorption measurements (Fig. 3). Table S1† summarizes the pore sizes, specific surface areas (SSAs), and total pore volumes (TPVs) of both samples. P/C has possessed a high BET surface area of $596 \mathrm{~m}^{2} \mathrm{~g}^{-1}$; after introducing $\mathrm{Fe}$ in the synthesis process, it is dramatically increased to $1269 \mathrm{~m}^{2} \mathrm{~g}^{-1}$. The high surface area without the use of any template may be due to the pore-generating ability of the starting precursor. At a sufficiently high temperature, phytic acid releases its six molecules of orthophosphate, which are removed from the surface of carbon as $\mathrm{CO}_{2}$ gas and generate mainly micropores in the carbon framework. ${ }^{44,45}$ The higher surface area of $\mathrm{FeP} / \mathrm{C}$ can be ascribed to its higher total pore volume. Its pore size distribution (Fig. 3b) indicates the micro-/ meso-porous structure of both samples. While FeP/C shows a sharp and strong peak at a pore diameter of $1.5 \mathrm{~nm}, \mathrm{P} / \mathrm{C}$ shows a similar peak at $1.8 \mathrm{~nm}$. Both samples show a peak around $2.9 \mathrm{~nm}$. It is confirmed that the $\mathrm{FeP} / \mathrm{C}$ is highly porous in nature with a high surface area. The large surface area and abundant micro/meso-pores provide sufficient channels for the efficient diffusion of the electrolyte and facilitate the accumulation of electrons on the electrode surface in the electrochemical system. This is expected to achieve stable and high performance as electrode materials for supercapacitor and ORR applications. ${ }^{46,47}$

The supercapacitor (SC) performances of $\mathrm{P} / \mathrm{C}$ and $\mathrm{FeP} / \mathrm{C}$ samples were investigated by cyclic voltammetry (CV) and galvanostatic charge/discharge (GCD) measurements in
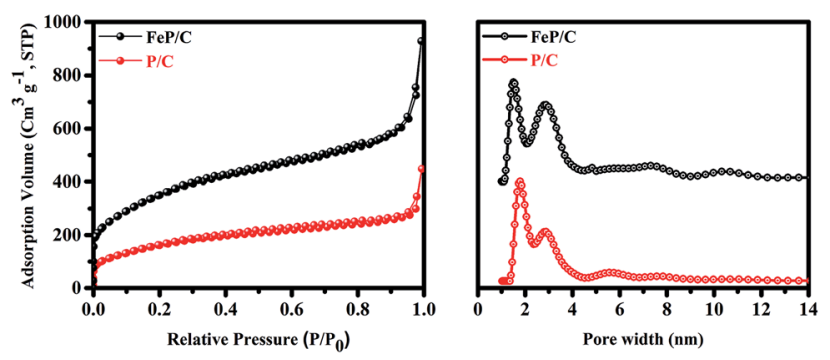

Fig. $3 \quad \mathrm{~N}_{2}$ adsorption-desorption isotherms and pore size distribution curves of $\mathrm{P} / \mathrm{C}$ and $\mathrm{FeP} / \mathrm{C}$. 
a conventional three-electrode configuration at room temperature using $3 \mathrm{M} \mathrm{KOH}$ solution as an electrolyte. Fig. 4a shows a comparison of the $\mathrm{CV}$ curves of $\mathrm{P} / \mathrm{C}$ and $\mathrm{FeP} / \mathrm{C}$ obtained at a scan rate of $100 \mathrm{mV} \mathrm{s}^{-1}$. Both samples show a quasirectangular shape, indicating an electric double layer capacitive behavior. The FeP/C electrode shows a considerably higher current density than that of $\mathrm{P} / \mathrm{C}$, revealing the higher capacitance of $\mathrm{FeP} / \mathrm{C}$ based on the directly proportional relationship between the CV curve area and capacitance. The CV curves were also obtained by varying the scan rate for both samples, $\mathrm{P} / \mathrm{C}$ (Fig. S4a $\dagger$ ) and FeP/C (Fig. 4b). The good symmetry shown indicates a good rate capability.

The GCD curves of $\mathrm{P} / \mathrm{C}$ and $\mathrm{FeP} / \mathrm{C}$ are depicted in Fig. $\mathrm{S} 4 \mathrm{~b} \dagger$ and $4 \mathrm{c}$, respectively. Curves of $\mathrm{P} / \mathrm{C}$ exhibit nearly triangular traces at various current densities, showing the capacitive behavior of the prepared sample. In contrast, the discharging curve in the $\mathrm{FeP} / \mathrm{C}$ sample shows an initially sharp potential drop, especially at the current density of $1.2 \mathrm{~mA} \mathrm{~cm}^{-2}$, which returns back to the internal resistance (ohmic resistance). This IR drop mainly arises from the internal resistance of $\mathrm{FeP} / \mathrm{C}$ due to the migration of ions between the electrode and electrolyte. ${ }^{48}$ Fig. S5 $\uparrow$ shows the change of areal capacitance with current density for both samples. The $\mathrm{P} / \mathrm{C}$ shows better rate capability than that of $\mathrm{FeP} / \mathrm{C}$. This can be understood in the light of the pore size of both samples (Table $\mathrm{S} 1 \dagger$ ), where the reversible adsorption/desorption of electrolyte ions on the surface of electrodes determines the electric double layer (EDL) capacitance. At low current densities, electrolyte ions can easily access the inner micro- and meso-pores through holes on the $\mathrm{P} / \mathrm{C}$ and $\mathrm{FeP} / \mathrm{C}$. However, at high current densities, the small pores may reduce the ions' movements. Therefore, the capacitance decreases significantly in the $\mathrm{FeP} / \mathrm{C}$ sample. ${ }^{49}$

The areal capacitances $\left(C_{\mathrm{A}}\right)$ of both electrodes were estimated based on the galvanostatic discharge curves. The $C_{\mathrm{A}}$
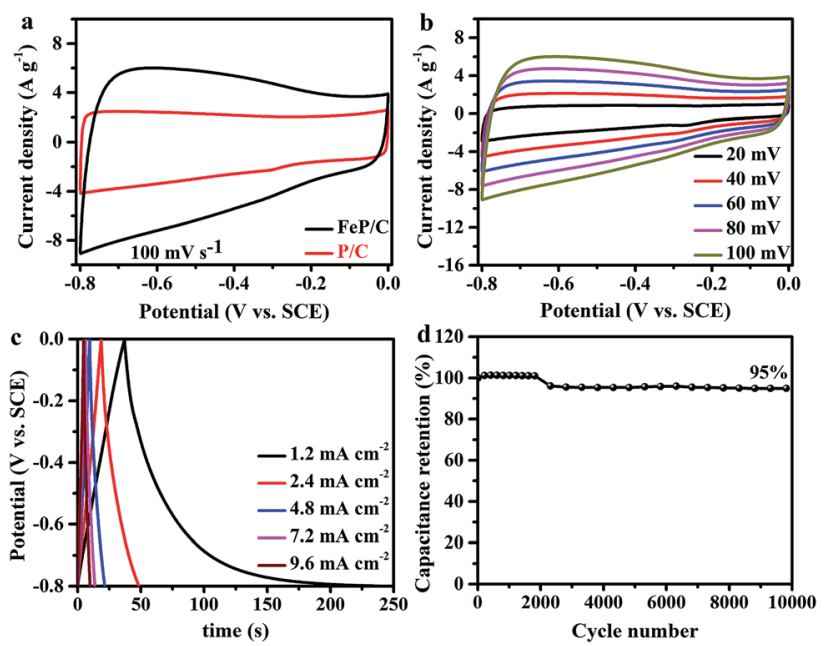

Fig. 4 Electrochemical properties measured in a three-electrode system using $3 \mathrm{M} \mathrm{KOH}$ as an electrolyte. (a) CV curve comparison of P/ $\mathrm{C}$ and FeP/C at $100 \mathrm{mV} \mathrm{s}^{-1}$ scan rate, (b) CV curves of FeP/C at various scan rates, (c) GCD curves of FeP/C at different current density, and (d) the cycling performance of $\mathrm{FeP} / \mathrm{C}$ at $100 \mathrm{mV} \mathrm{s}^{-1}$. values of $\mathrm{P} / \mathrm{C}$ and $\mathrm{FeP} / \mathrm{C}$ achieve 41 and $313 \mathrm{mF} \mathrm{cm}^{-2}$ at a current density of $1.2 \mathrm{~mA} \mathrm{~cm}^{-2}$, respectively. The specific capacitance values of $\mathrm{P} / \mathrm{C}$ and $\mathrm{FeP} / \mathrm{C}$ at an equivalent current density of $1 \mathrm{~A} \mathrm{~g}^{-1}$ correspond to 34 and $261 \mathrm{~F} \mathrm{~g}^{-1}$, respectively. The obtained areal capacitance of $\mathrm{FeP} / \mathrm{C}$ is close to or considerably better than some previously reported iron-based materials. Table $\mathrm{S} 2 \dagger$ shows data comparing its electrochemical performance with those of some previously reported Fe-based materials.

The electrochemical stability of the electrode material was evaluated using long-term cycling performance at a scan rate of $100 \mathrm{mV} \mathrm{s}^{-1}$ for 10000 cycles (Fig. 4d). It is well known that because of structural deformation during the long-time charge/ discharge process, iron-based supercapacitor electrode materials often suffer from poor stability. ${ }^{\mathbf{5 0 , 5 1}}$ In previous studies, arrays from $\mathrm{FeP}$ nanotubes and nanorods were used as negative electrodes for supercapacitor application and showed only $41 \%$ and $24.19 \%$ retention after 5000 cycles, respectively. ${ }^{29,31}$ After coating FeP nanorod arrays with PEDOT, the stability increased to $82.1 \% .^{31}$ Porous N/P co-doped carbon showed capacitance retention of $86.3 \%$ after 10000 cycles. $^{52}$ Interestingly, FeP/C exhibits outstanding cycle performance and retains $95 \%$ of its initial capacitance value after 10000 cycles, indicating the synergetic effect of the coupling of FeP and carbon.

The electrochemical activities of the as-synthesized samples toward ORR were studied in $\mathrm{O}_{2}$ - and $\mathrm{N}_{2}$-saturated $0.1 \mathrm{M} \mathrm{KOH}$ solutions by cyclic voltammetry $(\mathrm{CV})$ at a scan rate of $100 \mathrm{mV} \mathrm{s}^{-1}$ (Fig. 5a and S6†). It is clear in Fig. 5a that the CV curves in the $\mathrm{N}_{2}$-saturated solution did not display any characteristic reduction peaks, while the same electrodes in the $\mathrm{O}_{2}$-saturated solution display characteristic peaks on the cathodic scan at about 0.52 and $0.68 \mathrm{~V}$ vs. RHE for $\mathrm{P} / \mathrm{C}$ and $\mathrm{FeP} / \mathrm{C}$, respectively. Moreover, as shown in Fig. S6, $\uparrow$ the area under the FeP/C curve is clearly higher than that of $\mathrm{P} / \mathrm{C}$, indicating the increase in ORR
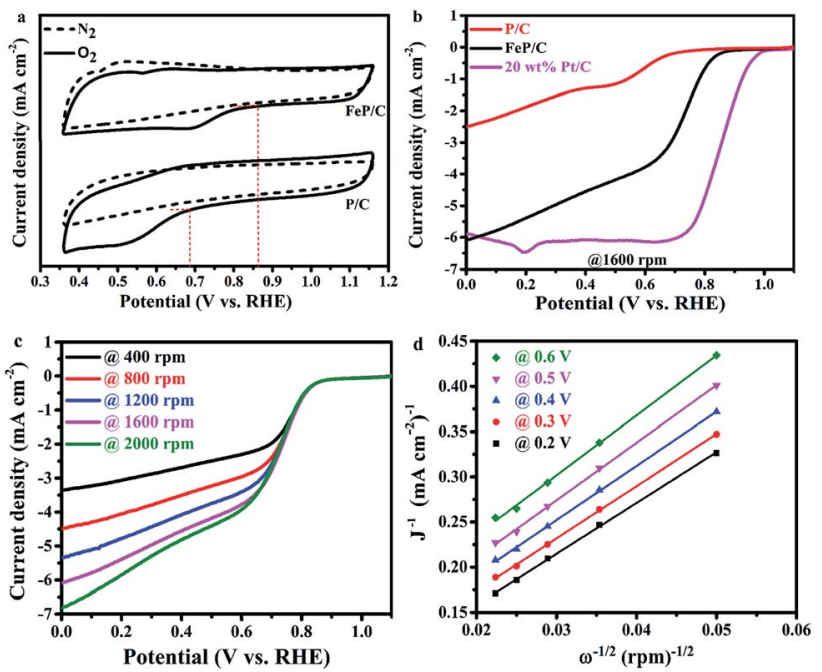

Fig. 5 ORR measurements in a three-electrode system using $0.1 \mathrm{M}$ $\mathrm{KOH}$ as an electrolyte. (a) CV curve comparison of $\mathrm{P} / \mathrm{C}$ and $\mathrm{FeP} / \mathrm{C}$ at $100 \mathrm{mV} \mathrm{s}^{-1}$, (b) LSV curve comparison of P/C, FeP/C, and $20 \mathrm{wt} \% \mathrm{Pt} / \mathrm{C}$ at $1600 \mathrm{rpm}$, (c) LSV curves of FeP/C at different rotation rates, and (d) Koutecky-Levich plots at different potentials. 
active sites with the introduction of Fe. The ORR curves of FeP/C are well defined with the most positive onset potential ( $c a$. $0.86 \mathrm{~V} v s$. RHE), which is 180 and $20 \mathrm{mV}$ more positive than those of P/C (Fig. 5a) and a previously reported Fe-phosphate/ $\mathrm{C},{ }^{41}$ respectively.

The ORR kinetics of $\mathrm{P} / \mathrm{C}$ and FeP/C have been studied by linear sweep voltammetry (LSV) through RRDE measurements at rotation speeds ranging from 400 to $2000 \mathrm{rpm}$ with a scan rate of $10 \mathrm{mV} \mathrm{s}^{-1}$ (Fig. 5b and c). The LSV curves of assynthesized FeP/C show a more positive value of onset potential $(0.86 \mathrm{~V} v s$. RHE) than that of prepared $\mathrm{P} / \mathrm{C}(0.68 \mathrm{~V} v s$. RHE), as shown in Fig. 5b. Also, the half-wave potential values of FeP/ $\mathrm{C}, \mathrm{P} / \mathrm{C}$, and commercial Pt/C are estimated to be $0.74 \mathrm{~V}, 0.59 \mathrm{~V}$, and $0.86 \mathrm{~V}$ ( $v s$. RHE), respectively. These results indicate the better ORR catalytic activity of prepared $\mathrm{FeP} / \mathrm{C}$ than that of $\mathrm{P} / \mathrm{C}$ sample in $0.1 \mathrm{M} \mathrm{KOH}$ solution. Interestingly, the limiting current density of our $\mathrm{FeP} / \mathrm{C}$ electrode at $0 \mathrm{~V}$ vs. RHE was a little bit higher than that of the commercial Pt/C electrode. Fig. S7 $\dagger$ shows the differences in the potential and limiting current density values of the three electrodes. The higher ORR activity of FeP/C than P/C may be due to the higher surface area, the presence of sufficient $\mathrm{P}-\mathrm{C}$ interactions which break the electroneutrality of carbon, and the presence of $\mathrm{Fe}$ atom which helps to break the $\mathrm{O}=\mathrm{O}$ bonds..$^{51-55}$

Using the Koutecky-Levich plot, the electrons transferred per $\mathrm{O}_{2}$ molecule $(n)$ during ORR at different potentials $(0.2,0.3$, $0.4,0.5$, and $0.6 \mathrm{~V} v s$. RHE) were calculated, as shown in Fig. $5 \mathrm{~d}$. The obtained K-L plots show high linearity, suggesting firstorder reaction kinetics based on our measurement conditions. ${ }^{56}$ The average electron number is 4.6 for $\mathrm{FeP} / \mathrm{C}$, which reveals the preferred $\mathrm{H}_{2} \mathrm{O}$ formation mechanism. ${ }^{36,57}$

In further study, the electron transfer numbers and hydrogen peroxide percentage were calculated by using the currents obtained from disk and ring electrodes through RRDE measurement in the potential range of $0.0-0.7 \mathrm{~V} v s$. RHE (Fig. 6). ${ }^{37}$ As shown in Fig. 6b, electron transfer number values are around 4 along all selected potential ranges, which is consistent with the results obtained by K-L plot analysis. The hydrogen peroxide yield is between $1.4 \%$ and $5.7 \%$, which agrees with a previously reported study of Fe-phosphate/C material, ${ }^{41}$ which overcomes the reported defects of phosphate-based ORR electrocatalysts. ${ }^{58}$ Such a high electron transfer number and low $\mathrm{H}_{2} \mathrm{O}_{2}$ percentage are very important,
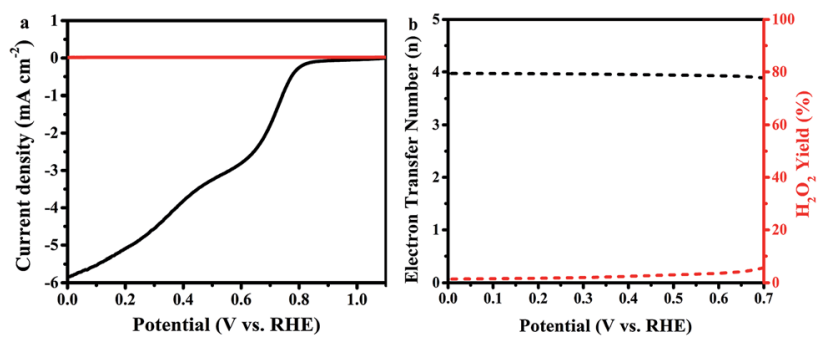

Fig. 6 (a) RRDE test of the ORR on FeP/C in an $\mathrm{O}_{2}$-saturated $0.1 \mathrm{M}$ $\mathrm{KOH}$ electrolyte at a scan rate of $10 \mathrm{mV} \mathrm{s}^{-1}$ and a rotating rate of 1600 rpm; (b) assessment of electron transfer number and peroxide percentage in ORR catalyzed by FeP/C based on RRDE data. according to the operating point of view that requires protection of the catalyst layer and membrane from degradation by crossover $\mathrm{H}_{2} \mathrm{O}_{2} .{ }^{59}$

The stability of the $\mathrm{FeP} / \mathrm{C}$ electrode was investigated using chronopotentiometry measurements at a constant potential (0.46 V vs. RHE) in $\mathrm{O}_{2}$-saturated $0.1 \mathrm{M} \mathrm{KOH}$ at $1600 \mathrm{rpm}$ as a rotation speed and compared with the benchmark Pt/C catalyst (Fig. S8†). The as-synthesized FeP/C electrode retains $84 \%$ of its initial current value after 9000 seconds, a bit better than $20 \mathrm{wt} \% \mathrm{Pt} / \mathrm{C}$, which shows $81 \%$ current retention under the same measurement conditions. All of the above results highlight the promising application of $\mathrm{FeP} / \mathrm{C}$ as an electrode for ORR applications.

\section{Conclusions}

In summary, we have successfully synthesized $\mathrm{FeP} / \mathrm{C}$ material using an eco-friendly and simple hydrothermal method followed by carbonization. $\mathrm{FeP} / \mathrm{C}$ sample shows a high surface area $\left(1269 \mathrm{~m}^{2} \mathrm{~g}^{-1}\right)$ that is mainly microporous with the presence of mesopores. FeP/C has been also investigated as an electrode for supercapacitor and ORR applications using a three-electrode system. The electrochemical properties of $\mathrm{P} / \mathrm{C}$ are significantly improved by incorporating Fe. When FeP/C is used as a supercapacitor electrode, it exhibits a maximum areal capacitance of $313 \mathrm{mF} \mathrm{cm}{ }^{-2}$ at a current density of $1.2 \mathrm{~mA} \mathrm{~cm}^{-2}$, accompanied by $95 \%$ capacitance retention after 10000 cycles. While in use as an electrode material for ORR in an alkaline medium, it illustrated high electrocatalytic activity and exhibited a positive shift value of onset potential ( $0.86 \mathrm{~V} v s$. RHE) and high limiting current at $0 \mathrm{~V} v s$. RHE with the production of a low percentage from hydrogen peroxide. It also provided a four-electron transfer pathway with $84 \%$ current retention after 9000 seconds. The reported results would provide useful information for the development of metal phosphide based electrodes with high performance for supercapacitor and ORR applications.

\section{Conflicts of interest}

There are no conflicts to declare.

\section{Acknowledgements}

The project was supported by the National Natural Science Foundation of China (NSFC) (61604070) and the National Natural Science Foundation of Jiangsu Province (BK20161000). Ahmed K. Yousef appreciates the financial support by the joint supervision scholarship from the cultural affairs and missions sector, the Egyptian Ministry of Higher Education (MOHE). The authors acknowledge the Deanship of Scientific Research (DSR) at King Abdulaziz University, Jeddah for technical and financial support. This work was performed in part at the Queensland node of the Australian National Fabrication Facility, a company established under the National Collaborative Research Infrastructure Strategy to provide nano- and microfabrication facilities for Australia's researchers. 


\section{References}

1 B. Liu, Y. Sun, L. Liu, J. Chen, B. Yang, S. Xu and X. Yan, Energy Environ. Sci., 2019, 12, 887-922.

2 M. Watanabe, M. L. Thomas, S. Zhang, K. Ueno, T. Yasuda and K. Dokko, Chem. Rev., 2017, 117, 7190-7239.

3 M. Winter and R. J. Brodd, Chem. Rev., 2004, 104, 4245-4270.

4 K. Jost, D. P. Durkin, L. M. Haverhals, E. K. Brown, M. Langenstein, H. C. De Long, P. C. Trulove, Y. Gogotsi and G. Dion, Adv. Energy Mater., 2015, 5, 1401286.

5 Y. Wang and Y. Xia, Adv. Mater., 2013, 25, 5336-5342.

6 P. Simon and Y. Gogotsi, Nat. Mater., 2008, 7, 845-854.

7 J. Zhang, Z. Zhao, Z. Xia and L. Dai, Nat. Nanotechnol., 2015, 10, 444-452.

8 K. Gong, F. Du, Z. Xia, M. Durstock and L. Dai, Science, 2009, 323, 760-764.

9 H.-W. Liang, W. Wei, Z.-S. Wu, X. Feng and K. Müllen, J. Am. Chem. Soc., 2013, 135, 16002-16005.

10 B. E. Conway, Electrochemical supercapacitors: scientific fundamentals and technological applications, Springer Science \& Business Media, 2013, pp. 11-31.

11 Z. Lin, E. Goikolea, A. Balducci, K. Naoi, P.-L. Taberna, M. Salanne, G. Yushin and P. Simon, Mater. Today, 2018, 21, 419-436.

12 R. Zhao, L. Zhang, C. Wang and L. Yin, J. Power Sources, 2017, 353, 77-84.

13 L. L. Zhang and X. S. Zhao, Chem. Soc. Rev., 2009, 38, 25202531.

14 W. Wei, J. Wu, S. Cui, Y. Zhao, W. Chen and L. Mi, Nanoscale, 2019, 11, 6243-6253.

15 Q. Liu, L. Du, G. Fu, Z. Cui, Y. Li, D. Dang, X. Gao, Q. Zheng and J. B. Goodenough, Adv. Energy Mater., 2019, 9, 1803040.

16 M. Lefèvre, E. Proietti, F. Jaouen and J.-P. Dodelet, Science, 2009, 324, 71-74.

17 L. Yang, J. Shui, L. Du, Y. Shao, J. Liu, L. Dai and Z. Hu, Adv. Mater., 2019, 31, 1804799.

18 W. Wei, S. Cui, L. Ding, L. Mi, W. Chen and X. Hu, ACS Appl. Mater. Interfaces, 2017, 9, 40655-40670.

19 H. S. Kim, M. S. Kang and W. C. Yoo, J. Mater. Chem. A, 2019, 7, 5561-5574.

20 Z. Peng, Y. Hu, J. Wang, S. Liu, C. Li, Q. Jiang, J. Lu, X. Zeng, P. Peng and F. F. Li, Adv. Energy Mater., 2019, 9, 1802928.

21 G. Wu, K. L. More, C. M. Johnston and P. Zelenay, Science, 2011, 332, 443-447.

22 J.-J. Zhou, X. Han, K. Tao, Q. Li, Y.-L. Li, C. Chen and L. Han, Chem. Eng. J., 2018, 354, 875-884.

23 D. Kong, C. Cheng, Y. Wang, J. I. Wong, Y. Yang and H. Y. Yang, J. Mater. Chem. A, 2015, 3, 16150-16161.

24 Z. Sun, M. Zhu, X. Lv, Y. Liu, C. Shi, Y. Dai, A. Wang and T. Majima, Appl. Catal., B, 2019, 246, 330-336.

25 Y. Yu, J. Ma, C. Chen, Y. Fu, Y. Wang, K. Li, Y. Liao, L. Zheng and X. Zuo, ChemCatChem, 2019, 11, 1722-1731.

26 K. N. Dinh, Q. Liang, C.-F. Du, J. Zhao, A. I. Y. Tok, H. Mao and Q. Yan, Nano Today, 2019, 25, 99-121.

27 B. C. Martindale and E. Reisner, Adv. Energy Mater., 2016, 6, 1502095.
28 T.-Q. Zhang, J. Liu, L.-B. Huang, X.-D. Zhang, Y.-G. Sun, X.-C. Liu, D.-S. Bin, X. Chen, A.-M. Cao and J.-S. Hu, J. Am. Chem. Soc., 2017, 139, 11248-11253.

29 B. Liang, Z. Zheng, M. Retana, K. Lu, T. Wood, Y. Ai, X. Zu and W. Zhou, Nanotechnology, 2019, 30, 295401.

30 C. Guan, J. Liu, Y. Wang, L. Mao, Z. Fan, Z. Shen, H. Zhang and J. Wang, ACS Nano, 2015, 9, 5198-5207.

31 J. Luo, Z. Zheng, A. Kumamoto, W. I. Unah, S. Yan, Y. H. Ikuhara, X. Xiang, X. Zu and W. Zhou, Chem. Commun., 2018, 54, 794-797.

32 V. D. Nithya and N. S. Arul, J. Power Sources, 2016, 327, 297318.

33 X. Wang, K. Chen, G. Wang, X. Liu and H. Wang, ACS Nano, 2017, 11, 11602-11616.

34 H. Fan, H. Liu, X. Hu, G. Lv, Y. Zheng, F. He, D. Ma, Q. Liu, Y. Lu and W. Shen, J. Mater. Chem. A, 2019, 7, 11321-11330.

35 A. M. Zardkhoshoui and S. S. H. Davarani, J. Alloys Compd., 2019, 773, 527-536.

36 J. Duan, S. Chen, S. Dai and S. Z. Qiao, Adv. Funct. Mater., 2014, 24, 2072-2078.

37 R. Zhou, Y. Zheng, M. Jaroniec and S.-Z. Qiao, ACS Catal., 2016, 6, 4720-4728.

38 H. B. Aiyappa, S. Saha, P. Wadge, R. Banerjee and S. Kurungot, Chem. Sci., 2015, 6, 603-607.

39 S. Dou, L. Tao, J. Huo, S. Wang and L. Dai, Energy Environ. Sci., 2016, 9, 1320-1326.

40 W. Weisweiler, N. Subramanian and B. Terwiesch, Carbon, 1971, 9, 755-761.

41 K. P. Singh, E. J. Bae and J.-S. Yu, J. Am. Chem. Soc., 2015, 137, 3165-3168.

42 G. B. B. Varadwaj and V. O. Nyamori, Nano Res., 2016, 9, 3598-3621.

43 W. Wei, W. Chen, L. Ding, S. Cui and L. Mi, Nano Res., 2017, 10, 3726-3742.

44 A. M. Puziy, O. I. Poddubnaya, A. Martínez-Alonso, F. SuárezGarcía and J. M. Tascón, Carbon, 2005, 43, 2857-2868.

45 M. A. Nahil and P. T. Williams, Biomass Bioenergy, 2012, 37, 142-149.

46 A. E. Allah, Y. Yamauchi, J. Wang, Y. Bando, H. Tan, A. A. Farghali, M. H. Khedr, A. Alshehri, Y. G. Alghamdi, D. Martin, M. A. Wahab, M.-d. A. Hossain and A. K. Nanjundan, ChemElectroChem, 2019, 6, 1-8.

47 S. Liu, H. Zhang, Q. Zhao, X. Zhang, R. Liu, X. Ge, G. Wang, H. Zhao and W. Cai, Carbon, 2016, 106, 74-83.

48 A. Pendashteh, M. S. Rahmanifar, R. B. Kaner and M. F. Mousavi, Chem. Commun., 2014, 50, 1972-1975.

49 J. Wang, T. Park, J. W. Yi, B. Ding, J. Henzie, Z. Chang, H. Dou, X. Zhang and Y. Yamauchi, Nanoscale Horiz., 2019, 4, 526-530.

50 R. Li, Y. Wang, C. Zhou, C. Wang, X. Ba, Y. Li, X. Huang and J. Liu, Adv. Funct. Mater., 2015, 25, 5384-5394.

51 Y. Zeng, M. Yu, Y. Meng, P. Fang, X. Lu and Y. Tong, Adv. Energy Mater., 2016, 6, 1601053.

52 Y. Zhang, Q. Sun, K. Xia, B. Han, C. Zhou, Q. Gao, H. Wang, S. Pu and J. Wu, ACS Sustainable Chem. Eng., 2019, 7, 57175726. 
53 H. Tan, Y. Li, J. Kim, T. Takei, Z. Wang, X. Xu, J. Wang, Y. Bando, Y.-M. Kang and J. Tang, Adv. Sci., 2018, 5, 1800120.

54 L. Yang, S. Jiang, Y. Zhao, L. Zhu, S. Chen, X. Wang, Q. Wu, J. Ma, Y. Ma and Z. Hu, Angew. Chem., Int. Ed., 2011, 50, $7132-7135$.

55 C. H. Choi, S. H. Park and S. I. Woo, ACS Nano, 2012, 6, 70847091.

56 X. Fan, Y. Liu, Z. Peng, Z. Zhang, H. Zhou, X. Zhang, B. I. Yakobson, W. A. Goddard III, X. Guo and R. H. Hauge, ACS Nano, 2017, 11, 384-394.
57 L. Zhang, J. Zhang, D. P. Wilkinson and H. Wang, J. Power Sources, 2006, 156, 171-182.

58 M. Pramanik, C. Li, Y. V. Kaneti and Y. Yamauchi, Chem. Commun., 2017, 53, 5721-5724.

59 X.-Z. Yuan and H. Wang, PEM fuel cell electrocatalysts and catalyst layers: fundamentals and applications, Springer Science \& Business Media, 2008, pp. 1-87. 